\title{
War experiences and emerging rights claims in postwar former Yugoslavia: The role of generalized conflict exposure and collective anomie
}

\author{
Dario Spini, Davide Morselli (iD \& Guy Elcheroth \\ Swiss National Center for Competence in Research LIVES, University of Lausanne, Lausanne, Switzerland
}

\author{
Correspondence \\ Dario Spini, Swiss National Centre of \\ Competence in Research LIVES, University \\ of Lausanne, Géopolis Building, Lausanne \\ CH-1015, Switzerland. \\ E-mail: dario.spini@unil.ch \\ Received: 14 September 2016 \\ Accepted: 26 September 2018 \\ https://doi.org/10.1002/ejsp.2549 \\ Conflict of Interest Statement \\ The author declare they don't have any \\ conflict of interest concerning this \\ manuscript.

\section{Ethical Statement} \\ When the TRACES survey was conducted, \\ no formal ethical clearance procedure was \\ requested. \\ Transparency Statement \\ The TRACES data are publicly available and \\ free of charges at the Data and Research \\ Information Services (DARIS, FORSbase) of \\ the Swiss Foundation for Research in the \\ Social Sciences: https://forsbase.unil.ch/ \\ project/study-public-overview/10989/0/.
}

\begin{abstract}
Violent conflicts have often been observed to generate social environments in which human rights violations are more easily tolerated and legitimized. However, recent research has documented cases in which communities exposed to violence react with increased condemnations of human rights violations. In this article, we focus on the distinction between generalized and particularized violence. Our findings show that, in the postwar exYugoslavia context, when local communities have been exposed to violence that was generalized across different ethno-national groups, they strongly condemn human rights violations. Multilevel structural equation models show that the relationship between generalized victimization and the condemnation of human rights violations is mediated by a collective sense of anomie. The processes that move from collective exposure to violence to the collective reaffirmation of human rights are more likely to unfold in communities where violence transcended group boundaries than in communities where particular groups were disproportionately affected by the violence.
\end{abstract}

Keywords: collective victimization, anomie, war, human rights, postwar former Yugoslavia, ethnic conflict
In times of drastic sociopolitical change, the social fabric of communities can be threatened to the point that a climate of anomie or a culture of violence spreads (Somasundaram, 2014; Steenkamp, 2005; Zhao \& Cao, 2010). Research consistent with Durkheimian transitional theory has shown that rapid social change tends to result in an increment of suicides, crime, and deviant behavior (Bjarnason, Thorlindsson, Sigfusdottir, \& Welch, 2005; Durkheim, 1951/1897; Merton, 1957; Thorlindsson \& Bernburg, 2004). According to this theoretical framework, social norms weave the social fabric that provides a common ground on which people can decode and anticipate the actions of others (Chwe, 2013). Looseness of this fabric leads to a climate of protracted uncertainty and fear (Hwang $\delta$ Burgers, 1999).

When drastic social change has been caused by violent means, the resulting blurring of social norms is more likely and vehement. It is well documented that a legacy of systematic violence can pervade a society deeply and well beyond the end of armed conflict. The comparison of international homicide rates before and after armed conflicts demonstrates that criminal activities are systematically higher in the aftermath of war than they are before its inception (Archer \& Gartner, 1984). When state, religious, or other societal authorities legitimize killing, destroying, looting, or even raping during wartime, these behaviors can eventually become perceived as heroic and praiseworthy.

Such reversals of ordinary social norms occurred during the fratricidal dissolution of the former Yugoslavia. Testimonies from the witnesses of atrocities in Bosnia sometimes describe bewildering brutality and a discomforting sense of righteousness among the people who committed them (Silber \& Little, 1997; Wilmer, 2002). Overall, the wars in the former Yugoslavia resulted in the separation of communities, a surge in intergroup prejudice and nationalistic claims, and difficulties with reconstruction and reconciliation (Ringdal \& Simkus, 2012; Sekulic, Massey, \& Hodson, 2006; 
Spini, Elcheroth, \& Corkalo Biruski, 2014). This collective legacy therefore creates the risk that violent behaviors will remain less taboo in everyday life after the war.

However, even the worst cases of violence are not exempt from examples of resistance, humanity, or solidarity across conflict lines (Broz, 2005). For example, Whitt and Wilson (2007) discovered signs of intergroup fairness in an experimental setting in postwar Bosnia and Herzegovina. In this experimental setting, although people tended to engage in preferential treatment for their own ethnic group, norms of fairness were stronger than expected, and the overall level of favoritism remained relatively low. More generally, world history has shown that even the most devastating conflicts can be followed by calls to reconstruct normative contracts and efforts to protect people from violence. Thus, after witnessing the bloodshed at the battlefields of Solferino, Henri Dunant established the first universal humanitarian principles and founded the Red Cross in 1863; similarly, in the aftermath of World War II, the United Nations General Assembly adopted the Universal Declaration of Human Rights in 1948. Indeed, human rights have origins in collective violence (Turner, 2006).

To understand such seemingly antagonistic historical and social processes that relate collective violence to social norms, we must deepen our knowledge of the psychosocial dynamics and motives that either contain or precipitate the erosion of social norms and of how different types of violence affect these dynamics differently. In this study, we focus on the distinction between generalized and particularized violence. When violence is one-sidedly directed toward particular subgroups, it creates a social environment in which different groups have been divided by different fates, with little opportunity to bridge experiences and problematize beliefs that personal welfare is first and foremost tied to one's group fate. In such circumstances, any lingering sense of anomie is likely to be overridden by a prolonged state of collective alertness, where people remain mobilized for their own group's cause. As shown in a recent study by Penic, Elcheroth, and Morselli (2017), these conditions are the breeding grounds for the sacralization of ingroup norms and for the marginalization of intergroup contacts that might problematize them. Conversely, when the impact of violence spreads over entire communities - beyond particular subgroups - it creates a context in which it is difficult to uphold a belief in the uncontestable nature of group boundaries and in the binding social norms that are rooted in group experience. Our interest in the present work therefore lies in determining whether people who have been affected by generalized violence are more likely to perceive the norms in their (postwar) community as troubled and whether the collective sense of anomie that derives from generalized violence facilitates calls for more inclusive forms of social norms, such as human rights.

\section{Collective Victimization and Support for Human Rights}

The association between attitudes toward human rights and collective experiences was first established in a large comparative study by Doise, Spini, and Clémence (1999), who demonstrated that stronger perceptions of collective injustice were associated with more positive attitudes toward human rights. More recently, a series of studies have focused empirically on the conditions under which these seemingly paradoxical effects occur. Using secondary analyses of the People on War data, an international survey conducted in 1999 by the International Committee of the Red Cross in countries affected by armed conflict, Elcheroth (2006) found that although personal victims of war were less likely to condemn breaches in humanitarian law, postwar societies with higher rates of war victims displayed higher aggregate levels of the condemnation of such breaches. These results were then confirmed in a study concerning the former Yugoslavia that was conducted by Elcheroth and Spini (2009), which demonstrated that populations who collectively endured systematic human rights violations were more critical of national authorities and less tolerant of rights violations. In this study, exposure to war-related collective violence had a similar effect on support for different types of human rights, including humanitarian, judicial, and socio-economic rights. Elcheroth and Spini (2009) have interpreted this pattern as a spillover effect from human rights that have been collectively experienced as massively violated, such as violations of humanitarian principles in the context of the former Yugoslavian postwar societies. The effect of these serious rights violations spills over into different domains of human rights, including rights that have not been directly challenged, such as socio-economic rights. According to this spillover effect that shows that similar attitudes are found toward different types of rights (see also Spini \& Doise, 2005), we indistinctively use the concept of human rights here to refer to the reactions to the violations of many different types of human rights that are studied in the present research.

Additional multilevel analyses of the People on War dataset by Spini, Elcheroth, and Fasel (2008) introduced a generalization of risk index (GRI) to measure the convergence of exposure to traumatizing war events across the different subgroups that are involved in a conflict. This index differentiates generalized violence from particularized violence in terms of its concrete human impact on the general population (for related indicators that differentiate between symmetric and asymmetric forms of violence, see Penic, Elcheroth, \& Spini, 2018; Penic et al., 2017). In these analyses, which were processed at three levels-namely, individuals, conflicting groups and conflict systemsindividual victimization, active participation in combat, and partisanship were all negatively associated with the condemnation of human rights violations (CHRV). Null results were found at the group level: 
The number of victims in the in-group had no effect on the CHRV. However, at the system level, the GRI fully mediated the positive effects of the magnitude of war on the CHRV. In this comparative study, experiences of more generalized violence were thus associated with a stronger CHRV.

\section{Anomie, Collective Violence, and Human Rights}

When exposed to systematic violence, communities experience a blurring of moral references. This moral blur echoes the classic concept of anomie, which is defined as a state of normative disorder and a disintegration of the social fabric (Crutchfield $\&$ Bates, 2000). Although contemporary studies tend to analyze and measure anomie at the level of the individual (Seeman, 1991), anomie was defined in its classic Durkheimian formulation as a characteristic of society and a collective phenomenon (Bernard, 1987; Durkheim, 1951/1897). A growing body of research, notably in criminology and sociology, has tested hypotheses that relate to anomie based on multilevel analyses (Baumer, 2007; Thorlindsson \& Bernburg, 2004). Our conceptualization of anomie similarly recaptures the term's classical meaning as a characteristic of a specific collective climate that is rooted in shared experience. When exposure to collective violence is generalized across groups, the sense of anomie is not restricted to specific subgroups; instead, the resultant moral confusion affects even otherwise privileged or powerful groups (Beck, 1992; Elcheroth \& Spini, 2007; Spini et al., 2008). Following this line of thought, collective climates of anomie are expected to mediate the (positive) relationship between the collective experience of generalized violence and popular condemnations of human rights violations.

\section{Limitations of Previous Studies and Present Goals}

Previous research on the relationship between collective victimization across groups and the CHRV has suffered from three different types of limitations, which we attempt to overcome.

First, previous comparative inquiries (Elcheroth, 2006; Spini et al., 2008) have relied on large societies or countries as contextual units. However, in many conflict-torn societies, the assumption that a country provides a homogenous context may not be accurate (Arriaza \& Roht-Arriaza, 2008). A lack of homogeneity is particularly true in the case of the former Yugoslavia. For example, in Bosnia-Herzegovina or Croatia, some regional communities were not directly exposed to combat, and some communities were exposed to symmetric warfare between armed combat units; however, in other places, civilian populations were targeted in highly asymmetric settings of mass violence (Fasel \& Spini, 2016; Penic, 2014). Moreover, recent developments in spatial approaches to multilevel analyses rely on the idea that social contexts are not necessarily bounded by dichotomous, physical, or institutional borders; rather, they should be considered somewhat permeable spaces in which collective experiences unfold and spread (Elcheroth et al., 2013). Thus, it is important to study war exposure at a community level, to discover local variability in collective experiences, and to model how the effects of these collective experiences on moral climates spread across neighboring communities.

Second, previous investigations have been limited in their methods of recording group memberships. For example, in People on War, interviewers directly coded the "ethnic" membership of survey respondents as if it was a self-evident and visible trait of the individual. However, the relationship between visible markers of identity and the social affiliations important in conflict settings varies with respect to moment and location, especially when ethnicity is politicized in a context of collective violence (Reicher, 2004). In this article, we therefore employ data that enable us to define communal memberships according to multidimensional indicators, including external markers of identity and self-categorization.

Third, previous analyses were performed on data that did not include direct measures of anomie. Here, we test for the first time the mediation of the positive association between the GRI and the condemnation of human rights by collective climates of anomie. In combination with the survey design, the collected survey responses of people's sense of anomie allows us to disentangle the individual-level and contextual-level effects of anomie on the CHRV. We can thus test the hypothesis that collective anomie is a consequence of generalized risk in local communities and mediates its effects, that is, the more war exposure transcends group boundaries, the more people will perceive a sense of collective anomie and thus condemn human rights violations.

Three objectives thus guide the present study. Following Spini et al. (2008), the first objective is to replicate the positive relationship between collective exposure to generalized violence and collective intolerance toward human rights violations. In particular, we expect $(\mathrm{Hl}$, path $a$ in Figure 1) to find a higher CHRV in regions where war-related risks were generalized across ethno-national groups. The second objective is to explore whether support for human rights is similarly related to a stronger collective sense of anomie. Therefore, we hypothesize that $\left(\mathrm{H} 2 \mathrm{a}\right.$, path $b_{1}$ in Figure 1) anomie is positively associated with the CHRV. By following the Durkheimian approach, we also expect that $(\mathrm{H} 2 \mathrm{~b})$ this relationship is stronger at the collective level than it is at the individual level $\left(b_{2}>b_{1}\right.$ in Figure 1), that is, that intolerance toward human rights violations is driven by the experience of living in an environment where many people see norms as troubled rather than by a personal sense of anomie. The third objective combines and extends the previous objectives to test the new theoretical hypothesis that (H3) the relationship between exposure to generalized 


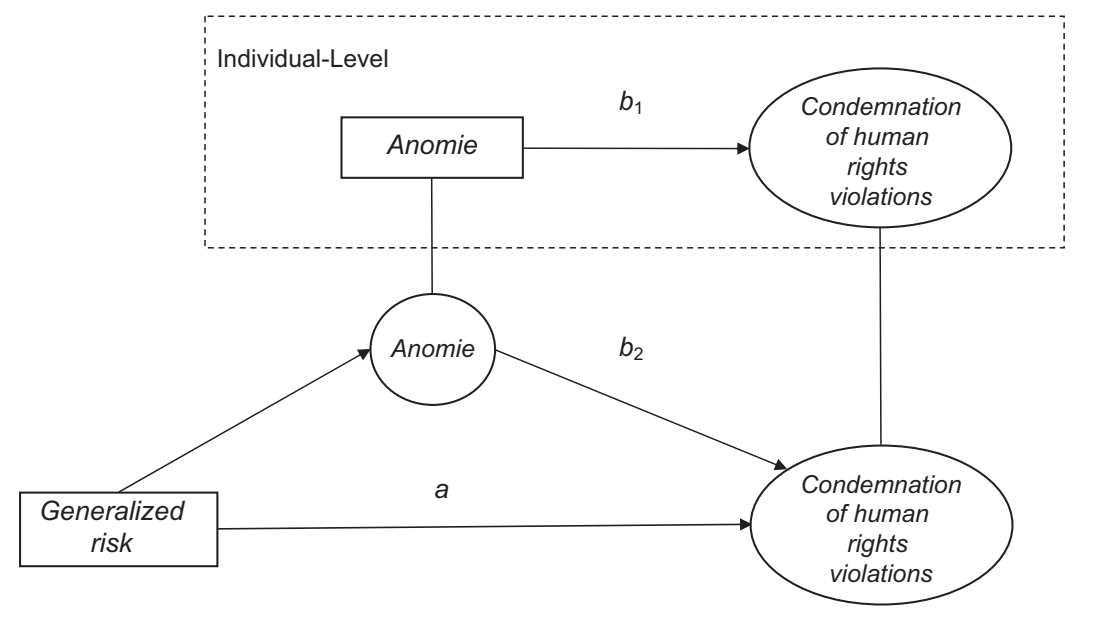

Context-Level

Fig. 1: Graphical representation of the hypotheses

violence and the condemnation of violations of human rights is mediated by a collective sense of anomie.

\section{Methods}

\section{Sample}

The Transition to Adulthood and Collective Experiences Survey (TRACES ${ }^{1}$; Spini, Elcheroth, \& Fasel, 2011; Spini et al., 2014) was conducted between April and December 2006. The former Yugoslavian territory was stratified into 80 regions identified by regional subdivisions within the current state boundaries and the boundaries of subnational political entities (i.e., Federation of Bosnia and Herzegovina/Republika Srpska; Serbia/Kosovo/Montenegro/Vojvodina; for a detailed description of the survey, see Spini et al., 2011). Regions were geographically contiguous and defined as a set of municipalities. Municipalities were aggregated to have a similar number of inhabitants in each region. Regions were then clustered into six political entities, namely, Slovenia, Bosnia, Croatia, Serbia-Montenegro, ${ }^{2}$ Kosovo, and the Former Yugoslav Republic of Macedonia (FYROM).

\footnotetext{
${ }^{1}$ The TRACES data are publicly available and free of charges at the Data and Research Information Services (DARIS, FORSbase) of the Swiss Foundation for Research in the Social Sciences: https://forscenter.ch.

${ }^{2}$ At the time of the survey, Serbia, Montenegro, Vojvodina, and Kosovo were part of the State Union of Serbia and Montenegro (SUSM). The interviews were conducted during Montenegro's process of achieving independence from Serbia. Indeed, following the results of the referendum in May 2006, Montenegro declared independence on June 3, 2006, which marked the end of the SUSM. At the time of this writing, the Republic of Kosovo is a self-declared and partially recognized independent state. Serbia does not recognize the secession of Kosovo and considers it an autonomous province (Kosovo and Metohija) that is governed by the UN. Because of both the small size of the sample in Montenegro and Vojvodina and Kosovo's unique experience of war compared with the other SUSM regions, we divided Serbia, Montenegro, and Vojvodina from Kosovo and combined them into one political unit called Serbia-Montenegro.
}

In 2006, when the TRACES survey was conducted, no formal ethical clearance procedure was requested. The procedure for collecting data was adopted by a consortium of Croat, Serb, and Swiss researchers and involved several ethical considerations, including explaining that respondents could withdraw from the research at any time, excluding overly sensitive questions (i.e., post-traumatic symptoms), and training interviewers to manage different ethical issues during the fieldwork.

The sampling design of the survey aimed to overrepresent the ethnic or national groups that represented between $5 \%$ and $10 \%$ of the population of the former Yugoslavia in order to compute the statistical estimates for the six largest ethno-national subgroups, that is, Albanians, Bosniaks, Croats, Slovenes, Macedonians, and Serbs. Concerning the former Yugoslavia, ethno-national groups were defined by regional affiliation (e.g., Skopje), religion (e.g., Muslim), and language spoken (e.g., Albanian). These three categories are the essential features by which an individual can be identified as a member of an ethno-national group.

Two samples were assembled (see Table 1 for the demographic characteristics). The first sample - that is, the general sample - was a random selection of approximately 50 respondents per region who belonged to the general adult population and who were born in 1981 or earlier. Given the absence of registry data in many postwar zones, participants were selected via a random walk technique based on a stratified random selection of municipalities and starting points (for details see Spini et al., 2011). The total number of respondents was 3,975 $($ Slovenia $=406 ; \quad$ Croatia $=850 ; \quad$ Bosnia-Herzegovina $=746$; Serbia and Montenegro $=876 ;$ Kosovo $=551$; FYROM $=546$ ). These respondents answered the first part of the questionnaire, which consisted of two life event calendars. First, they were asked to indicate whether, when, and for how long they had experienced certain war-related events between 1990 and 2006 (divided into quarters of years). Second, the respondents were asked to report events concerning their transition to adulthood (from 15 to 30 years old, divided into 
Table 1. Demographic characteristics of the two Transition to Adulthood and Collective Experiences Survey samples

\begin{tabular}{lccccc}
\hline & \multicolumn{2}{c}{ General sample } & & \multicolumn{2}{c}{ Cohort sample } \\
\cline { 2 - 3 } \cline { 5 - 6 } Variable & $M$ & SD & & $M$ & $S D$ \\
\hline Age & 42.13 & 14.13 & & 34.99 & 2.04 \\
Woman & $54 \%$ & - & & $51 \%$ & - \\
Education & & & & - \\
$\quad$ Primary & $22 \%$ & - & & $15 \%$ & - \\
Secondary & $57 \%$ & - & & $64 \%$ & - \\
Tertiary & $19 \%$ & - & & $19 \%$ & - \\
Ethno-national group & & & & - \\
Albanian & $15 \%$ & - & & $14 \%$ & - \\
Croat & $23 \%$ & - & $22 \%$ & - \\
Hungarian & $1 \%$ & - & & $1 \%$ & - \\
Macedonian & $10 \%$ & - & $11 \%$ & - \\
Montenegrin & $1 \%$ & - & & $1 \%$ & - \\
Bosniak & $10 \%$ & - & $11 \%$ & - \\
Serb & $24 \%$ & - & $26 \%$ & - \\
Slovene & $9 \%$ & - & $10 \%$ & - \\
Other & $6 \%$ & - & $5 \%$ & - \\
\hline
\end{tabular}

quarters of years). The responses from the general sample were used to compute the context-level indicators.

The second sample - the cohort sample - was a random selection of approximately 30 residents from each region who were born between 1968 and 1974, using the same procedure as the general sample. The respondents were 2,249 individuals who answered a series of attitudinal measures in addition to the life events calendar questionnaire. The final cohort sample size after the listwise deletion of

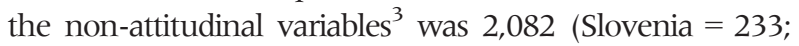
Croatia $=430 ; \quad$ Bosnia-Herzegovina $=434 ;$ Serbia and Montenegro $=408 ;$ Kosovo $=255 ;$ FYROM $=322$ ), which was stratified into 80 regions. The average number of respondents per region was 26 .

\section{Outcome Variables}

Condemnation of human rights violations was measured by three different categories of human rights, specifically humanitarian, judicial, and social rights.

\footnotetext{
${ }^{3}$ The number of missing values per item was generally below a threshold of 5\% (Hair, Tatham, Anderson, \& Black, 2006) in both samples. However, in Kosovo, 29\% of the Albanian respondents had more than five missing values in the variables of interest for this research. Thus, we decided to replace the missing values of the attitudinal measures through multiple imputations, which reduces bias and increases efficiency (King, Honaker, Joseph, \& Scheve, 2001; Schafer \& Olsen, 1998). The R package Amelia II (Honaker, Joseph, King, Scheve, \& Singh, 1999) was used to impute the missing values. Five imputed datasets were produced in two separate phases, namely, one for the independent variables and one for the dependent variables that were used in our analyses, by using 231 variables to impute the dependent variables and 228 variables to impute the independent variables. Diagnostic analyses of over-imputation showed a good reliability of the imputed values. The following analyses, which were performed with Mplus 7.11 (Muthén \& Muthén, 1998-2013), estimate the parameters over a set of five analyses and compute the standard errors by using both the average standard errors of the five datasets and the estimate of the between-analysis variation (Rubin, 1987; Schafer, 1997).
}

Three vignettes that described concrete cases of formally recognized violations based on court judgments were used as stimuli, which followed the example of previous work by Doise, Dell'Ambrogio, and Spini (1991) and Staerklé and Clémence (2004). The vignettes depicted a violation of the European Social Charter (social rights), a violation of International Humanitarian Law (humanitarian rights), and a case that was judged by the European Court of Human Rights (judicial rights) (see Appendix). The judicial vignette was newly designed for this research, whereas the vignettes concerning social and humanitarian rights were previously successfully employed by Elcheroth and Spini (2009). To minimize possible order effects, the vignettes appeared at different locations in the questionnaire. Between 26 and 39 other questions were asked between two vignettes.

After reading each vignette, the respondents had to answer four attitudinal questions concerning human rights ( $1=$ very strongly disagree; $7=$ very strongly agree), which were equivalent for each scenario regarding the extent of the condemnation of such norms. These items read as follows: "In such a situation, political leaders should take concrete measures to avoid this kind of treatment in the future"; "Even in a difficult economic period/such tragic events/difficult circumstances, such things should never happen; they are completely unacceptable"; "It does not make sense to blame political leaders within that country because there is not much they can do to modify people's behavior" (reverse-coded); and "Even if such a situation/war/treatment were undesirable, one has to accept it as an ordinary consequence of difficult circumstances/war" (reverse-coded). The results of the internal consistency of the scales were as follows. Regarding the condemnation of social rights violations, the Cronbach's $\alpha$ ranged from $\alpha=.59$ (Bosniaks and Albanians) to $\alpha=.71$ (Croats), and the average inter-item correlation ranged from $\rho=.26$ (Bosniaks and Albanians) to $\rho=.37$ (Croatia). Concerning the condemnation of humanitarian rights violations, the Cronbach's $\alpha$ ranged from $\alpha=.51$ (Macedonians) to $\alpha=.68$ (Croats) and average inter-correlations ranged from $\rho=.20$ (Macedonians) to $\rho=.32$ (Croats). With respect to the condemnation of judicial rights violations, the Cronbach's $\alpha$ ranged from $\alpha=.44$ (Bosniaks) to $\alpha=.67$ (Serbs) and average intercorrelations ranged from $\rho=.16$ (Bosniaks) to $\rho=.32$ (Serbs). ${ }^{4}$

\footnotetext{
${ }^{4}$ Cronbach's $\alpha$ is sensitive to the number of items; scales with few items tend to have small values of $\alpha$. The average inter-item correlation is insensitive to the number of items and, in our case, may be considered a better indicator of the internal reliability of the scale. According to Clark and Watson (1995), one-dimensional scales should have a $\rho$ that ranges from .15 to .50. In addition, our main analysis uses these three measures as indicators of a latent variable. As such, these measures are expected to contain some error variance, but this is accounted for in the measurement part of the model. The structure of the single indicators was also tested through structural equation modeling and showed that the structure of the scale was stable and invariant across the six translations of the questionnaire (i.e., Albanian, Bosniak, Croat, Macedonian, Serb, and Slovene). The results of the measurement invariance can be provided on request.
} 


\section{Individual-Level Explanatory Variables}

Conflict exposure. Two variables indicated the participants' passive or active involvement in armed conflicts. The first variable, war victim, was a binary variable that identified whether the respondent claimed to be affected by at least one of six war-related episodes of victimization, specifically, being wounded, suffering property damages, suffering the violent death of a family member, being imprisoned, having had their house looted, and being forced to leave home. The second variable, combatant, identified active participation in the conflict by coding 1 for the respondents who declared having used or carried weapons during conflicts and by coding 0 for the non-combatant respondents.

Anomie. The sense of normlessness was measured with McClosky and Schaar's (1965) anomie scale. The original scale consisted of nine items scored on a 7-point Likert scale ( $1=$ "strongly disagree"; 7 = "strongly agree"). Examples of the items are "With everything so uncertain these days, it almost seems as though anything could happen" and "Everything changes so quickly these days that I often have trouble deciding which are the right rules to follow". A twolevel exploratory factor analysis showed that items 7 and 9 loaded on a different factor than the other items at both the individual and context levels. ${ }^{5}$ Thus, we computed the anomie score as the average individual response to all items other than items 7 and 9. The scores ranged from 1 (low anomie) to 7 (high anomie). High scores indicate a sense of discouragement, social distrust, and normlessness. The reliability of the scale ranged from $\alpha=.73$ (Macedonians) to $\alpha=.85$ (Croats and Bosniaks) and from $\rho=.33$ (Serbs) to $\rho=.45$ (Croats).

Demographics. Analyses were conducted for age (in years), gender $(1=$ woman, $0=$ man $)$, and the level of education of the respondents (primary, secondary, and tertiary).

\section{Context-Level Explanatory Variables}

Although the common procedure in multilevel analysis involves modeling the contextual effects within bounded contextual units (e.g., within state or administrative boundaries), we applied multilevel modeling with spatially weighted context data (Elcheroth et al.,

\footnotetext{
${ }^{5}$ Although the scale is commonly used as an overall mean score across all nine items, exploratory factor analyses of Eastern European university student samples - that is, Bulgarian-were unable to replicate the unidimensionality of the scale (Ådnanes, 2007). Similarly, research on a representative sample of Belgian citizens (Perko, Turcanu, Schrö, \& Carlé, 2010) found that items 7 and 9 of the original scales had different patterns of answers than all the other items and loaded on a different factor in exploratory factor analyses with an oblimin rotation.
}

2013). This method considers the permeability of contextual boundaries and defines a continuous rather than a dichotomous relationship between events and social contexts. According to this conception of space, we computed proximity weights based on the geographical distances between regions, and we assumed that: (i) the contribution of an event that is located in a survey area is maximized within the boundaries of a political entity; and that (ii) this influence tends to fade beyond a certain threshold distance. Even when the sample size is relatively small, this method increases the reliability of the estimates of the contextual indicators that are constructed by aggregating individual data (e.g., the individual experience of victimization). In the present study, the bandwidth of the influence among regions was set at $97 \mathrm{~km}$, which is the average radius of the eight political entities.

Two indicators of contextual victimization - that is, overall victimization and the GRI-were calculated using the same self-reported experiences of victimization that were used for individual victimization.

Overall victimization was defined as the ratio of the number of episodes of victimization per quarter of a year within a region to the estimated total number of respondents per quarter of a year in the region. By using the spatial weighting procedure, war victimization was weighted by the geographical proximity between regions. Thus, the collective impact of victimization depended on the events that occurred in the geographically close regions (see Figure 2, left). The standardized values ranged from -1.59 in the Slavonian regions of Croatia (the counties of ViroviticaPodravina and Pozega-Slavonia) to 1.90 in central Bosnia (Srednjobosanski Canton).

The GRI was computed, following spini et al. (2008), based on the absolute differences in victim rates across $n$ groups according to Equation (1), where $r_{i}$ stands for the victim rates within the ethno-national groups $i$ and $j$.

$$
\text { GRI }=1-\sum_{i=1}^{n-1} \sum_{j=n+1}^{n}\left|r_{i}-r_{j}\right| \frac{n(n-1)}{2} .
$$

Ethno-national group membership was estimated based on how the respondents recalled their declaration of nationality in the 1990 census. For the respondents who did not provide this information or who declared themselves Yugoslavs in 1990, their ethnonational affiliation was defined based on their region of origin, the language spoken, and their religion. In the context of pre-conflict Yugoslavia, refusing to declare any affiliation to an ethno-national group or declaring an affiliation to the superordinate category of Yugoslavs may have reflected the desire to avoid contributing to ethnic divisions. However, regardless of how individuals identify themselves, they are likely to be targeted as members of a particular ethnic group based on their region of origin, language, and religion. Additionally, they may become victims of violence because of these ethnic markers. The resulting ethno-national 

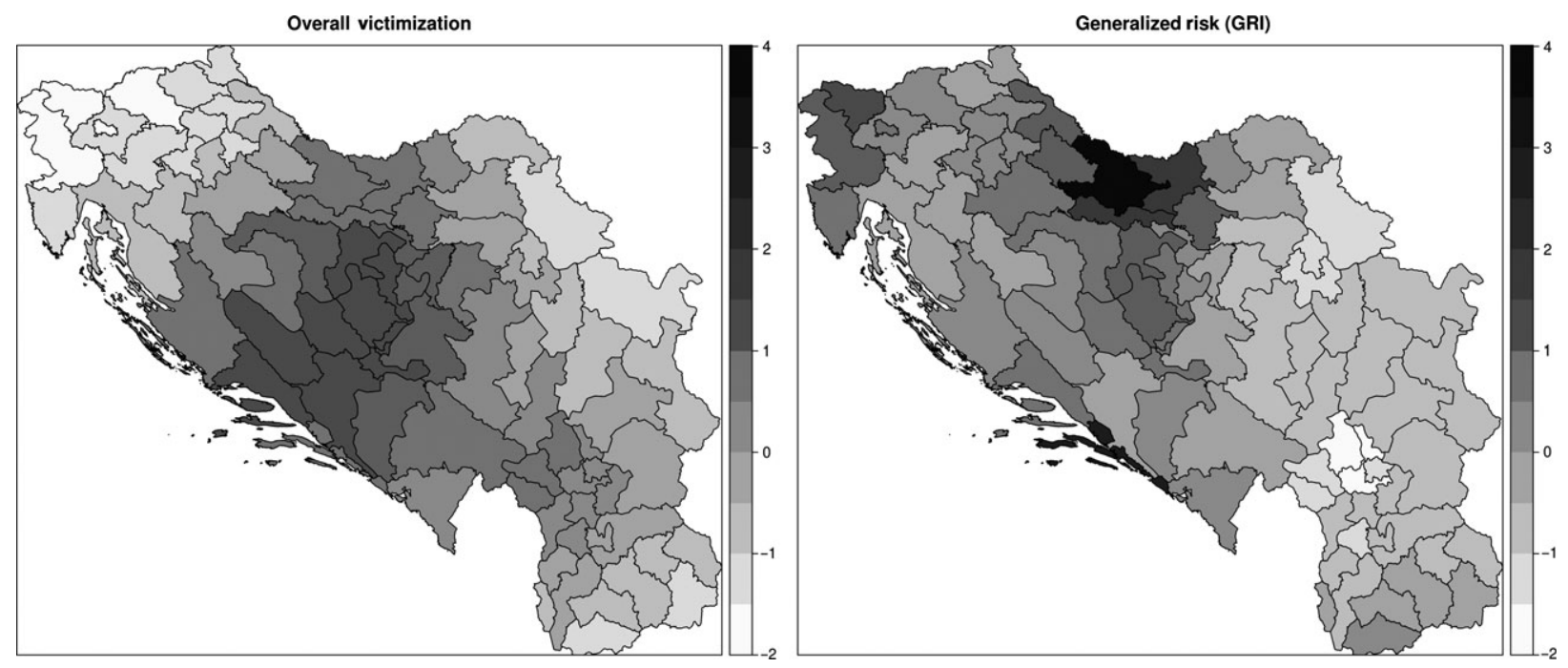

Fig. 2: Distribution of overall victimization (left) and generalization of risk (right) weighted by geographical proximity. Note: The gradient indicates standard deviations.

distribution is displayed in Figure 3 and approximates the distribution that is based on census data and population estimates.

To estimate the risks across groups in conflict, Equation (1) was applied to the ethno-national groups politicized during the armed conflicts in each political entity of the former Yugoslavia. The GRI was computed as the number of estimated episodes of victimization per quarter of a year within each of these ethno-national groups. In particular, we considered the following ethno-national groups: Serbs and Slovenians in Slovenia; Croats and Serbs in Croatia; Croats, Serbs and Bosniaks in Bosnia-Herzegovina; Serbs and Albanians in Kosovo; and Albanians and Macedonians in FYROM. A slightly more complicated situation had to be considered for Serbia, Montenegro and Vojvodina, where no open conflict occurred on the ground, although Serbia was involved in most of the conflicts in other parts of the former Yugoslavia. Thus, for this region, we included Serbs, the majority group, and the minority groups with which Serbs were openly in conflict elsewhere, that is, Croats, Bosniaks, and Albanians. ${ }^{6}$

High GRI scores indicate that the risk of being a victim is evenly distributed across groups, and low scores indicate that violence is particularized over one or several groups. The standardized values of the GRI ranged from -1.65 in the Mitrovica District in Kosovo to 3.52 in Slavonia (the county of Osijek-Baranja) in Croatia; central Bosnia (Zeničko-Dobojski canton) scored 1.27, and Slavonia ranged from 1.47 to 3.52 (see Figure 2, right). Therefore, the risk of being a

\footnotetext{
${ }^{6}$ An alternative indicator was computed that also included Slovenians. The two indicators did not remarkably differ; however, given the low level of victimization in the war in Slovenia, we considered it more appropriate to compare only Serbs, Croats, Bosniaks, and Albanians.
}

victim in Kosovo was mainly focused on the Albanian population. The conflict in Bosnia-Herzegovina was more symmetric, that is, the risk of victimization was shared to a higher degree across groups. Slavonia and Dalmatia represented the highest GRI regions; these regions were the stage for massive battles between Serb and Croat forces. A different case was found in Slovenia, where groups shared a generalized absence of risk because this territory was only marginally involved in conflict.

\section{Analytical Strategy}

Following Morselli, Spini, and Devos (2012), we used a particular type of multilevel structural equation modeling (ML-SEM), namely, the multilevel multiple indicators and multiple causes model (MIMIC; Bollen, 1989), in which one latent dimension underlies the outcome variables and is predicted by many explanatory variables that are controlled for covariance. In multilevel MIMIC, the variance of the outcome variable is divided between two levels, and the explanatory variables are inserted at both the individual (level-1) and context (level-2) levels. MIMIC models can therefore be combined with path analysis models to test the mediation and contextual effects. In our model, the context level was represented by the 80 regions under consideration, and the CHRV was treated as a latent dimension that explained the individual responses to violations of social, humanitarian, and judicial rights. The intraclass correlation coefficients (ICC) for the three indicators were .07 for judicial rights, .13 for social rights, and .14 for humanitarian rights. The model specified the CHRV at both levels, with factor loadings that were constrained to be equal at the two levels to lead to a measurement model that guaranteed that the CHRV at the context level was the average CHRV in each region. Although cross-level 


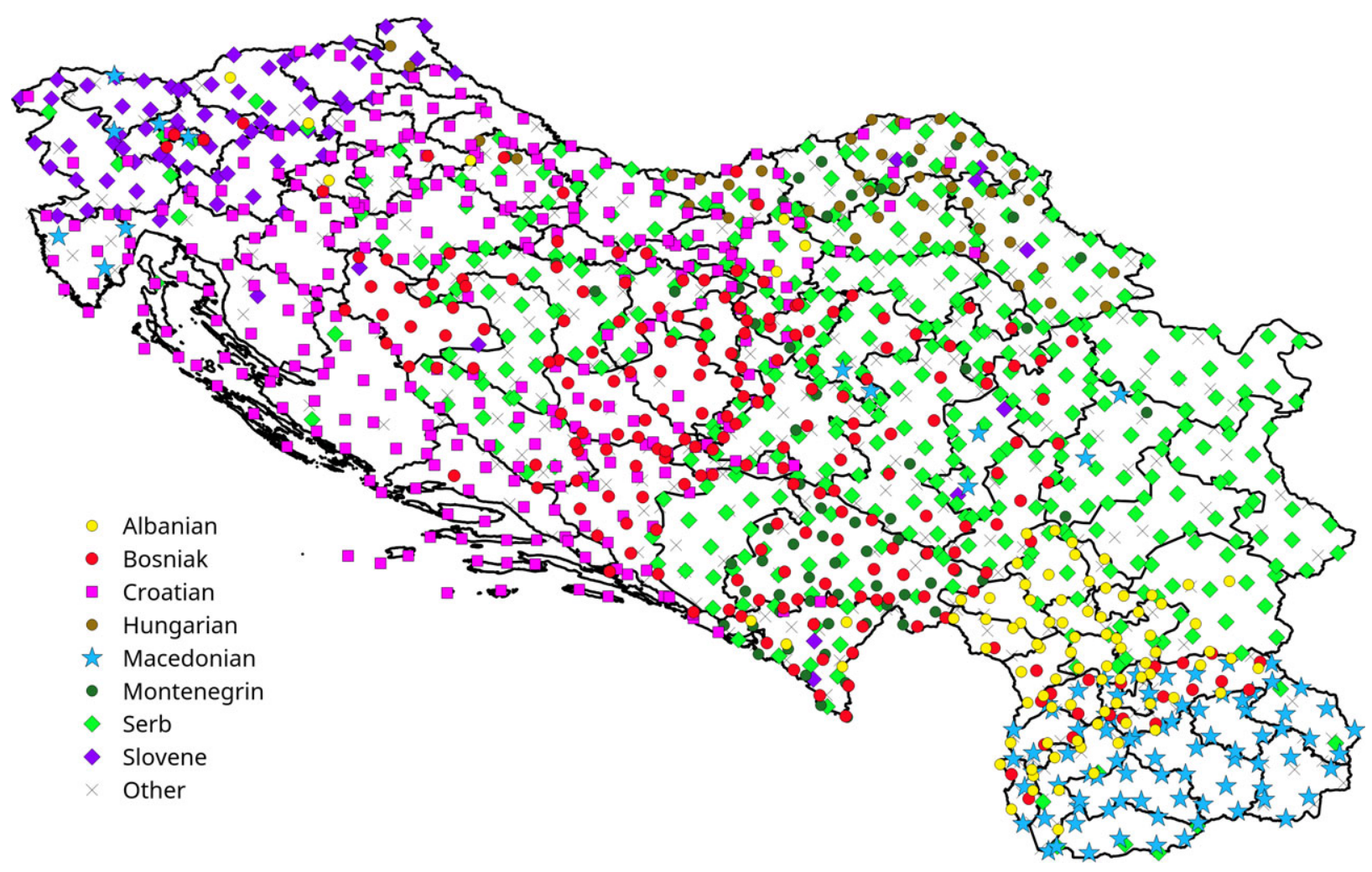

Fig. 3: Estimated ethno-national distribution in 2006

constraints in variance may not be fundamental to a multilevel factor analysis, they ensure the metric equivalence between the individual and context levels and facilitate interpretation (Marsh et al., 2009).

Four ML-SEM models were tested, where the CHRV was a latent dimension that explained the outcome variables at the individual and context levels. In Model 0 , only the individual explanatory and control variables were entered as the predictors of the latent variable at the individual level, which controlled for their covariance. In Model 1, overall victimization was inserted as a unique predictor of the CHRV at the context level. In Model 2, both the GRI and overall victimization were inserted into the equation, which controlled for their covariance. Model 3 tested the contextual effect of anomie and its mediation of the relationship between the GRI and CHRV. A two-level mediation model of type 2-1-1 (Preacher, Zyphur, \& Zhang, 2010) was tested with anomie as an individual-level variable that mediated the relationship between the GRI and the CHRV, as illustrated in Figure 4.

According to Preacher et al. (2010), the two-level mediation can be estimated by considering the variance component of individual-level variables at both the individual and context levels. This model estimates the relationship between the context-level variables and the context-level component of the individuallevel variables. Accordingly, the mediation model tests whether the context-level component of anomie mediates the relationship between the GRI and CHRV.
Thus, to estimate this mediation model, the variance of anomie was considered at both the individual and context levels $\left(\mathrm{ICC}_{\mathrm{anomie}}=.15\right)$ and centered on the grand mean (Enders \& Tofighi, 2007).

\section{Results}

\section{Descriptive Statistics}

Former Yugoslavian regions were involved at different levels in different types of conflicts (symmetric or asymmetric). To explore these differences, the TRACES sampling areas were divided into four different groups based on whether they scored above or below the grand means of the indicators of generalized risk and war victimization. Group 1 (low victimization, high GRI; V-/GRI+) included the regions marginally involved in armed conflict, such as most of the Slovenian regions. The regions in this group scored below average on war victimization and above average on the GRI. Therefore, in these regions, the social groups shared a condition of relative safety. The second category (Group 2) grouped the regions with relatively low average scores of victimization and a low GRI (V-/GRI-). In these regions, only particular groups, typically minority groups, experienced some form of victimization. Group 3 included the regions with high victimization and a low GRI (V+/GRI-). Such regions were heavily exposed to asymmetric violence. Kosovar 


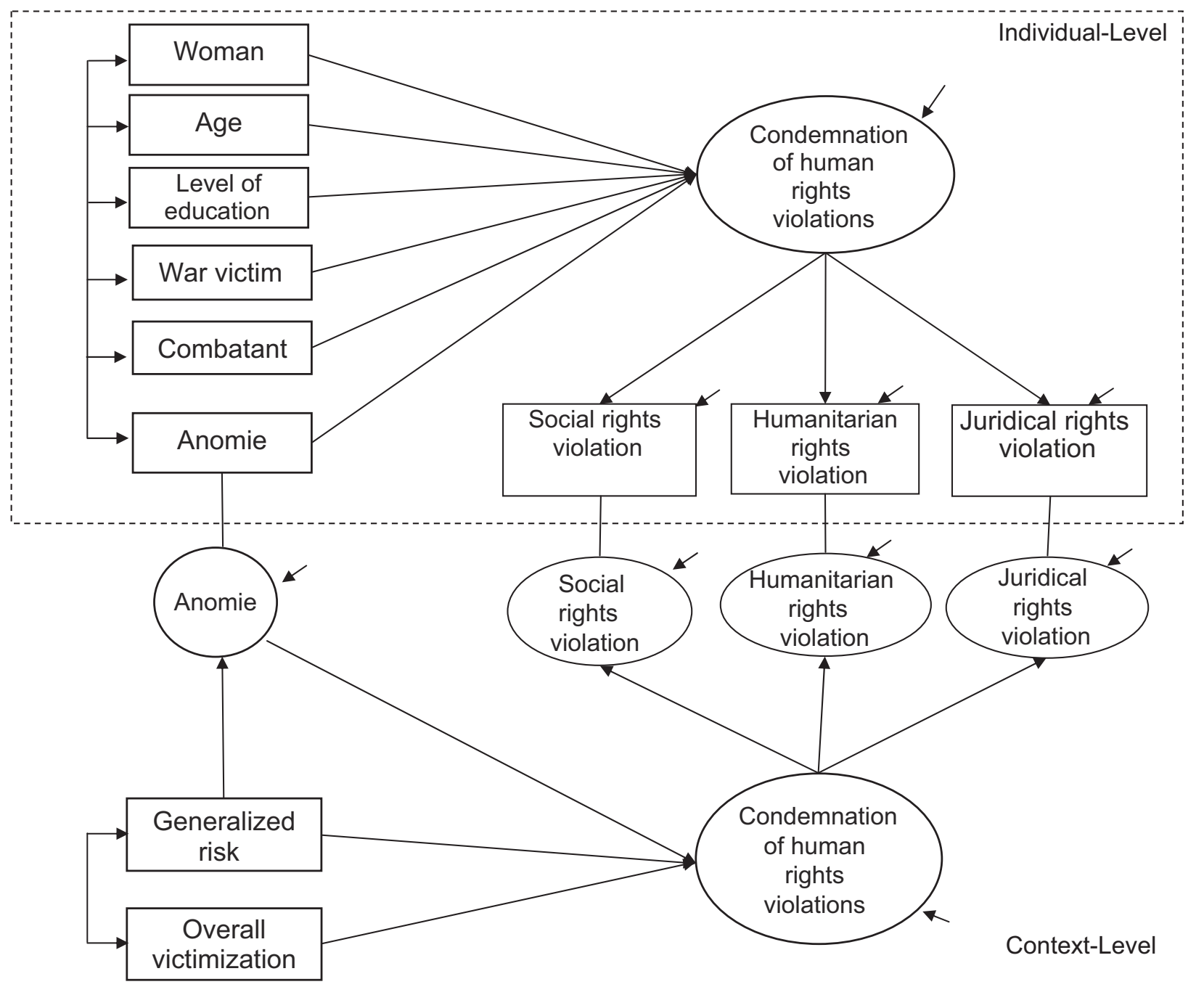

Fig. 4: Multilevel multiple indicator and multiple causes model with cross-level mediation

regions are included in this category. The last group (Group 4) describes the regions with above average victimization and GRI (V+/GRI+). In these regions (e.g., northeastern Croatia and most parts of Bosnia), combat was generalized, and the risk of being a victim was shared across all groups. The means and standard deviations of the variables of the present study are presented in Table 2 by groups of regions.

We believe that the division of the former Yugoslavia into these four groups describes more precisely the different context in which people lived and acted, rather than looking at national differences (e.g., Croatia, Serbia, etc.). Before and also partially during the war country boundaries were not impermeable, and conflict took place in relatively restricted areas across two countries. For instance, most of Serbia was not directly touched by the armed conflict, but the Serbian regions surrounding Bosnia and Croatia were heavily affected. Hence, country-level means would not properly describe the differences between contexts and possible contextual effects.

Victimization at the individual and context levels and the indicators of active involvement in combat provide a clear picture of contextual differences
(Table 2). The respondents experienced the war in very different ways depending on their geographical location. For example, $57-66 \%$ of the respondents in highly victimized regions experienced at least one episode of victimization during the conflicts, whereas victimization was $12 \%$ on average in the remaining parts of the former Yugoslavia. In addition, in the regions with high victimization and a high GRI, 33\% of the respondents indicated that they had played an active part in the armed conflict by using or carrying weapons. This proportion was almost twice as high as in the other regions.

Concerning the attitudinal variables, in the regions with high victimization but a low GRI, the measures of condemnation were appreciably lower than those in the other regions. The differences between Group 3 and the other groups were found to be significant in the Scheffe post hoc test for condemning the violation of judicial rights, $F(3,2,247)=6.53, p<.001$, social rights, $F(3,2,247)=32.70, p<.001$, and humanitarian rights, $F(3,2,247)=13.28, p<.001$. Similarly, the average level of the condemnation of rights violations was significantly lower in Group 3 than that in the other regions, $F(3,2,247)=7.97, p<.001$. 
Table 2. Means and standard deviations of individual and context variables (cohort sample)

\begin{tabular}{|c|c|c|c|c|c|c|c|c|c|c|}
\hline \multirow[b]{2}{*}{ Variable } & \multicolumn{2}{|c|}{$\begin{array}{c}\text { Group } 1 \\
\text { V-/GRI+ }\end{array}$} & \multicolumn{2}{|c|}{$\begin{array}{l}\text { Group } 2 \\
\text { V-/GRI- }\end{array}$} & \multicolumn{2}{|c|}{$\begin{array}{l}\text { Group } 3 \\
\text { V+/GRI- }\end{array}$} & \multicolumn{2}{|c|}{$\begin{array}{l}\text { Group } 4 \\
\text { V+/GRI+ }\end{array}$} & \multicolumn{2}{|c|}{ Overall } \\
\hline & $M$ & $S D$ & $M$ & $S D$ & $M$ & $S D$ & $M$ & $S D$ & $M$ & $S D$ \\
\hline \multicolumn{11}{|l|}{ Individual-level } \\
\hline SRV & 5.27 & 1.18 & 5.25 & 1.18 & 4.77 & 1.02 & 5.30 & 1.07 & 5.16 & 1.14 \\
\hline HRV & 5.46 & 1.07 & 5.49 & 1.11 & 5.16 & 1.09 & 5.54 & 1.06 & 5.42 & 1.10 \\
\hline JRV & 5.02 & 1.20 & 5.01 & 1.13 & 4.76 & 98 & 4.99 & 1.04 & 4.95 & 1.09 \\
\hline Anomie & 5.14 & 1.07 & 5.06 & 1.18 & 4.86 & 1.07 & 5.17 & 1.14 & 5.06 & 1.13 \\
\hline Victim of war & $12 \%$ & - & $12 \%$ & - & $68 \%$ & - & $57 \%$ & - & $36 \%$ & - \\
\hline Combatant & $14 \%$ & - & $15 \%$ & - & $17 \%$ & - & $33 \%$ & - & $20 \%$ & - \\
\hline \multicolumn{11}{|l|}{ Context-level } \\
\hline Overall victimization & -1.12 & 41 & -68 & 43 & 56 & 38 & 1.16 & 49 & - & - \\
\hline GRI & 69 & 50 & -58 & 31 & -86 & 48 & 1.01 & 99 & - & - \\
\hline
\end{tabular}

Note: -, low; +, high; GRI, Generalization of Risks Index; HRV, condemnation of human rights violation; JRV, condemnation of judicial rights violation; SRV, condemnation of social rights violation; $V$, victimization.

\section{Measurement Model}

A single-level multigroup confirmatory factor analysis was applied to test measurement invariance of CHRV defined by the indicators of condemnation of social, humanitarian, and judicial rights, across the different translations of the questionnaire. The analysis produced satisfying fit indexes in both the metric (CFI = .99; $\mathrm{RMSEA}=.01$; $\mathrm{SRMR}=.04)$ and scalar $(\mathrm{CFI}=.96$; RMSEA $=.06 ;$ SRMR $=.07)$ invariance models and showed comparable responses across the six languages, allowing us to assume the measurement invariance of the CHRV across languages.

We therefore tested the factor structure with a twolevel factor model with equal loading across levels. The model fit the data well: CFI $=1.00$; RMSEA $<.01$, within-SRMR $<.01$, and between-SRMR $<.02$. The factor loadings were all $>.70, p<.001$, and $21 \%$ of the variance of the latent variable was allocated to the context level.

\section{Generalization of Risks and Condemnation of Rights Violations}

The regression coefficients and the residuals of the four models are reported in Table 3, and Table 4 presents the covariance estimates of the individual predictors. The model fit was acceptable for the four models, with an increment of the context-level fit (between-SRMR) in Models 2 and 3.

Concerning the individual variables in Models 0-3, there were no significant effects of age and gender, of being a combatant or a partisan, or of individual victimization. These non-significant results were not expected. Nevertheless, because our main hypotheses were not related to individual-level variables, we did not interpret these results extensively. Level of education was positively associated with the CHRV, with better-educated respondents condemning the violations more frequently. According to our hypothesis (H2a), a sense of anomie is positively associated with the condemnation of rights violations, and the sense of anomie stands out as a highly significant individuallevel predictor of the CHRV, after controlling for other relevant factors. That is, individuals who perceived a higher sense of anomie were more likely to condemn a violation of rights. The explained variances of the CHRV at the individual level ranges from $14 \%$ in Models 0-2 to $11 \%$ in Model 3. The smaller explained variance in Model 3 results from considering the multilevel structure of the variance of anomie in this model.

At the context level, overall victimization was not a significant predictor of the CHRV in Model 1. Judgments on rights violations did not systematically differ between regions with high and low victimization. In contrast, Model 2 showed that the GRI was a positive and significant predictor of the CHRV, and it explained $7 \%$ of the variance at the context level. Consistent with our hypothesis (and in line with Spini et al., 2008) that generalized conflict exposure leads to a strong CHRV, in the regions with a higher generalization of risk, individuals are more likely to condemn a violation of rights (or conversely, where particular groups were more victimized than other groups, violations of rights are more legitimated).

\section{Contextual Effect of Anomie}

Model 3 tests the second part of our hypothesis (H2b) on the relationship between CHRV and anomie, according to which their relationship is stronger at the collective than the individual level. In this model the variance of anomie was considered concurrently as an individual- and context-level variable that predicts the CHRV.

The coefficient of anomie at the individual level was $B=.23, S E=.03, p<.001$. Congruent with our hypothesis, anomie had a consistent effect at the context level on the CHRV $(B=.56, S E=.10, p<.001)$. The difference between the individual- and contextlevel coefficients was .33, $S E=.10, p=.001$, which supports the hypothesis of a contextual effect of anomie. Thus, anomie is more predictive of the CHRV when 


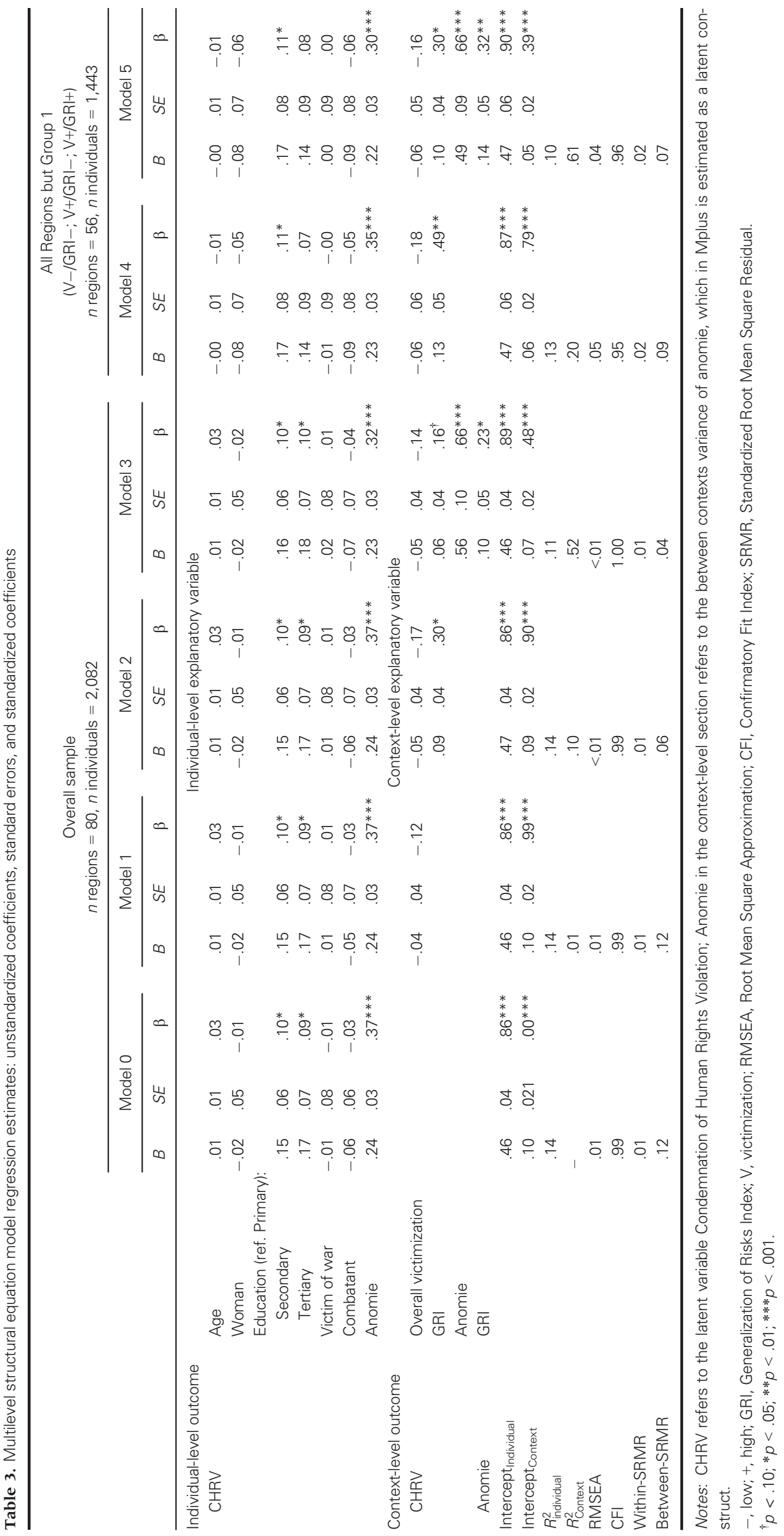


Table 4. Multilevel structural equation model unstandardized covariance estimates and standard errors (in parentheses) of individual-level predictors

\begin{tabular}{|c|c|c|c|c|c|c|}
\hline & \multicolumn{6}{|c|}{ Model 1 and 2} \\
\hline & Anomie & Age & Woman & Secondary education & Tertiary education & Victim \\
\hline Age & $.03(.05)$ & & & & & \\
\hline Woman & $.03(.01)^{*}$ & $.04(.02)$ & & & & \\
\hline Secondary education & $-.01(.02)$ & $.01(.02)$ & $-.02(.01)^{* * *}$ & & & \\
\hline Tertiary education & $-.02(.01)$ & $-.04(.02)^{*}$ & $.01(.01)^{* *}$ & $-.12(.01)^{* * *}$ & & \\
\hline Victim & $-.01(.02)$ & $.02(.02)$ & $-.09(01)^{* * *}$ & $-.01(.01)$ & $-.01(.01)^{* * *}$ & \\
\hline \multirow[t]{3}{*}{ Combatant } & $.02(.01)$ & $.07(.02)^{* *}$ & $-.01(01)$ & $.02(.01)^{* *}$ & $-.02(.01)^{* *}$ & $.03(.01)^{* * *}$ \\
\hline & \multicolumn{6}{|c|}{ Model 3} \\
\hline & Anomie & Age & Woman & Secondary education & Tertiary education & Victim \\
\hline Age & $.05(.05)$ & & & & & \\
\hline Woman & $.02(.01)$ & $.04(.02)$ & & & & \\
\hline Secondary education & $-.01(.02)^{* * *}$ & $.01(.02)$ & $-.02(.01)^{* * *}$ & & & \\
\hline Tertiary education & $-.01(.01)$ & $-.05(.02)^{*}$ & $.01(.01)^{* *}$ & $-.12(.01)^{* * *}$ & & \\
\hline Victim & $-.01(.02)$ & $.02(.02)$ & $-.09(.01)^{* * *}$ & $-.01(.01)$ & $-.01(.01) * * *$ & \\
\hline Combatant & $.01(.01)$ & $.07(.02)^{* *}$ & $-.01(-01)$ & $.01(.01)^{* * *}$ & $-.02(.01) * * *$ & $.03(.01)^{* * *}$ \\
\hline
\end{tabular}

Note: $* p<.05 ; * * p<.01 ; * * * p<.001$

inter-region variations, as opposed to inter-individual differences, are considered.

\section{Mediation of Anomie}

In addition to the contextual effect, Model 3 also tested the third and corollary hypothesis that the relationship between generalized conflict exposure and the condemnation of violations of rights is mediated by a collective sense of anomie. The results in Table 3 support this hypothesis and show that the GRI is a significant predictor of anomie at the context level. When anomie was considered as a contextual variable, the coefficient of the GRI on the CHRV dropped from $B=.09, \quad S E=.04, p<.01 \quad$ (Model 2) to $B=.06$, $S E=.04, p=.09$ (Model 3). The indirect effect of the GRI on the CHRV through anomie was IE $=0.06$ (95\% Confidence Interval: 0.01, 0.11), $S E=.03$, $p<.05$. The hypothesis concerning anomie's mediation of the effect of the GRI on the CHRV is therefore supported. Compared with Model 2, Model 3 displayed a $42 \%$ increase in the explained context-level variance. An alternative mediation model tested the indirect effect of overall victimization on the CHRV through anomie, but it did not produce significant results. The coefficient of anomie on overall victimization was $B=.01, S E=.06, p=.99$, and the indirect effect was IE $<0.01$ (95\% Confidence Interval: -0.07 , $0.07), S E=.04, p=.99$.

\section{Effect Sizes of Context-Level Predictors}

To better interpret and compare the magnitude of effects, we estimated the standardized effect sizes (ESs) that are associated with the context-level independent variables. However, multilevel models with latent variables require a more complex computation of ESs than single-level regression models require. Tymms
(2004) proposed an indicator of ES for the contextlevel predictors of multilevel models, which is comparable with Cohen's $d$. This ES is defined as the difference in the dependent variable between two areas that differ by two standard deviations on the contextlevel predictor. Tymms' ES is expressed in the formula

$$
\mathrm{ES}=\left(2^{*} \mathrm{~B}^{*} \mathrm{SD}\right) / \sigma_{\mathrm{e}}
$$

where $B$ is the unstandardized regression coefficient of the second-level explanatory variable, $S D$ is its standard deviation, and $\sigma_{\mathrm{e}}$ is the residual variance of the outcome variable. Although Tymms' ES is largely used in multilevel modeling, Marsh et al. (2009) argued that based on their experiences of meta-analyses, it is more appropriate to operationalize the ES in relation to the total variance of the outcome variable rather than in relation to the residual variance. Using Marsh et al.'s (2009) indications, the conservative standardized ES of overall victimization for Model 3 was $\mathrm{ES}=-.15$, which is considered a small effect. In contrast, the total effect of the GRI on the CHRV (i.e., the sum of the direct and indirect effects) was ES $=0.33$, and the contextual effect of anomie was ES $=0.39$. Both results are considered medium effects.

\section{Robustness Checks 1: Excluding Non-War Regions}

To further explore our hypotheses, we excluded from the analysis those regions in which the social groups shared a condition of non-risk (Group 1 regions). For instance, in the case of Slovenia the scores of GRI are quite high but with very low levels of victimization. Hence, it could be that positive association between GRI, anomie, and CHRV is not given by sharing the same traumatic experience, but because part of our respondents have never experienced the war directly, 
and thus it might be easier to condemn human right violations indiscriminately.

Models 4 and 5 in Table 3 replicated the models without Group 1 regions, which are the regions with high GRI and low overall victimization. The results of these two models are very similar to Models 2 and 3. The GRI was positively related to the CHRV, and this effect was partially mediated by collective anomie. These results suggest that the relationship between the GRI and the CHRV is not an artifact of sharing a relatively safe environment. They emphasize instead the role of experiencing of collective victimization, showing that the effect does not depend on a shared experience of war trauma in which "shared" means "none in all cases."

\section{Robustness Checks 2: Controlling for Ethno- National Affiliation}

Even if the dissolution of the former Yugoslavia is considered a collective experience that affected all parts and regions of the former Yugoslavia, some conflict characteristics overlapped with specific ethnic groups. For instance, Albanians in Kosovo experienced among the most asymmetric forms of violence, while during the Bosnian war-the only one in which Bosniaks were directly involved-different forms of violence heavily affected all involved groups.

To check that the relationship between the CHRV and anomie was not confounded by the specific ethno-national affiliation, Models 3 and 5 were replicated controlling for ethno-national affiliation at both levels. Similar to anomie, the variance of ethnonational affiliation was concurrently considered at both the individual and the context levels. It was therefore inserted in the model as a predictor of the CHRV and anomie at both levels. Models 6 and 7 in Table 5 show few effects of ethnicity on both variables. At the individual level, being Macedonian was positively associated with higher scores of anomie. However, this difference disappeared when the most secure regions (Group 1) were excluded from the analysis (Model 7). No relevant variation was observed at the context level. The effect of anomie on the CHRV was persistent at both levels. Notably, however, the context-level fit of this series of models was relatively poor. This poor fit was most likely caused by the high number of free parameters that add little explanatory power to the models. Accordingly, some caution should be taken in the substantive interpretation of these results.

\section{Discussion}

Many observers and participants in intractable conflicts have expressed pessimism concerning the "humanity" of the individuals and groups that have been involved in systematic and repeated violence in the aftermath of wars. Staub (2003), for example, states that past victimization affects people's assumptions about the world and "frustrates basic human needs like the need for security, for a positive identity, for a sense of effectiveness and control, for positive connections to others, and for a usable, meaningful comprehension of reality, including one's own place and role in the world" (p. 430). This general statement, which we translated as a description of collective anomie, led Staub (2003) to the straightforward conclusion that a group that is affected by violence "has an increased potential for violence" (p. 431). However, since the beginning of research on the social representations of human rights (Doise, 1988), two basic conclusions have been stated. The first one is more pessimistic and assumes that violence breeds a further denial of rights; the other relies instead on a constructive approach and shows that troubled norms can progress toward higher levels of justice and rights. The research that is represented here reinforces the second conclusion and clarifies its contours: Although social processes that lead to a further legitimization of violence can characterize the aftermath of particularized violence, collective exposure to generalized violence can be a starting point toward stronger support for human rights.

Previous research (Elcheroth, 2006; Elcheroth \& Spini, 2007, 2009; Spini et al., 2008) has shown that collective exposure to the systematic violence that threatens the integrity of a social system can trigger stronger popular claims for the enforcement of human rights, especially when this exposure is generalized across groups. We have demonstrated here a similar relationship concerning the aftermath of the violent conflicts in the former Yugoslavia. Our analyses provided support for the hypothesis according to which people endorse a stronger CHRV in regions where war-related risks generalized across ethno-national groups $(\mathrm{Hl})$. We have also extended previous findings by emphasizing the role that a collective sense of anomie plays in motivating human rights claims. In line with our second set of hypotheses, anomie was positively related to the support for human rights (H2a), and this relationship was stronger at the collective than the individual level (H2b).

These findings provide further empirical evidence that collective victimization is a driving force for the bottom-up support for human rights and add to a growing literature that challenges the assumption that repeated collective violence inevitably leads to a collapse of morality. Furthermore, the strengthening effect of collective victimization on the CHRV applies to different types of human rights. The results here further sustain the spillover hypothesis (Elcheroth $\delta$ Spini, 2009), which shows that a unique latent factor underlies the attitudes toward different types of rights.

The most striking result of this study involves the support for our third hypothesis (H3), which investigated the mediation of the effect of the generalization of risks on the CHRV by collective climates of anomie. Consistent with Durkheimian transitional theory, which posits that rapid social change is associated with higher levels of collective anomie (Zhao \& Cao, 2010), 
Table 5. Multilevel structural equation model regression estimates controlling for ethno-national affiliation: Unstandardized coefficients, standard errors, and standardized coefficients

\begin{tabular}{|c|c|c|c|c|c|c|c|}
\hline & & \multicolumn{3}{|c|}{$\begin{array}{c}\text { All regions } \\
\text { Model } 6\end{array}$} & \multicolumn{3}{|c|}{$\begin{array}{c}\text { All regions but Group } 1 \\
(\mathrm{~V}-/ \mathrm{GRI}-; \mathrm{V}+/ \mathrm{GRI}-; \mathrm{V}+/ \mathrm{GRI}+) \\
\text { Model } 7\end{array}$} \\
\hline & & $B$ & $S E$ & $\beta$ & $B$ & $S E$ & $\beta$ \\
\hline Individual-level outcome & \multicolumn{7}{|c|}{ Individual-level explanatory variable } \\
\hline \multirow[t]{7}{*}{ CHRV } & Anomie & .22 & .03 & $.31^{* * *}$ & .22 & .03 & $.30 * * *$ \\
\hline & Albanian & -.21 & .18 & -.05 & -.04 & .21 & -.01 \\
\hline & Croat & -.03 & .14 & -.01 & .03 & .18 & .01 \\
\hline & Macedonian & .20 & .20 & .04 & .23 & .30 & .03 \\
\hline & Bosniak & -.14 & .14 & -.04 & -.08 & .15 & -.02 \\
\hline & Serb & -.07 & .11 & -.02 & .04 & .11 & .01 \\
\hline & Slovene & .07 & .20 & .01 & -.52 & .25 & $-.03^{*}$ \\
\hline \multirow[t]{6}{*}{ Anomie } & Albanian & -.34 & .24 & -.05 & -.01 & .24 & -.00 \\
\hline & Croat & -.02 & .23 & -.00 & .00 & .28 & .00 \\
\hline & Macedonian & .98 & .34 & $.14^{* *}$ & .39 & .39 & .04 \\
\hline & Bosniak & -.13 & .18 & -.02 & -.02 & .18 & -.00 \\
\hline & Serb & .09 & .15 & .02 & .32 & .17 & $.08^{\dagger}$ \\
\hline & Slovene & .01 & .43 & .00 & -.10 & .45 & -.00 \\
\hline Context-level outcome & \multicolumn{7}{|c|}{ Context-level explanatory variable } \\
\hline \multirow[t]{9}{*}{ CHRV } & Overall victimization & -.06 & .05 & -.15 & -.11 & .06 & $-.28^{\dagger}$ \\
\hline & GRI & .06 & .05 & .15 & .06 & .06 & .19 \\
\hline & Anomie & .43 & .11 & $.51 * * *$ & .42 & .10 & $.57 * * *$ \\
\hline & Albanian & -.49 & .41 & -.38 & -.08 & .42 & -.07 \\
\hline & Croat & -.15 & .39 & -.16 & .26 & .37 & .28 \\
\hline & Macedonian & .10 & .40 & .08 & .17 & .41 & .07 \\
\hline & Bosniak & -.09 & .43 & -.06 & .34 & .43 & .27 \\
\hline & Serb & -.07 & .41 & -.07 & .20 & .39 & .22 \\
\hline & Slovene & -.28 & .38 & -.21 & -.24 & .35 & -.12 \\
\hline \multirow[t]{7}{*}{ Anomie } & GRI & .07 & .07 & .15 & .11 & .09 & .24 \\
\hline & Albanian & -.21 & .53 & -.14 & -.74 & .47 & -.51 \\
\hline & Croat & .29 & .53 & .25 & -.35 & .48 & -.27 \\
\hline & Macedonian & .79 & .50 & .50 & .57 & .47 & .17 \\
\hline & Bosniak & .32 & .69 & .17 & -.30 & .68 & -.17 \\
\hline & Serb & .26 & .60 & .21 & -.33 & .50 & -.27 \\
\hline & Slovene & .03 & .51 & .02 & -.77 & .43 & $-.29^{\dagger}$ \\
\hline$R_{\text {individual }}^{2}$ & & .12 & & & .10 & & \\
\hline$R_{\text {Context }}^{2}$ & & .61 & & & .68 & & \\
\hline RMSEA & & .03 & & & .03 & & \\
\hline $\mathrm{CFI}$ & & .92 & & & .91 & & \\
\hline Within-SRMR & & .02 & & & .03 & & \\
\hline Between-SRMR & & .14 & & & .15 & & \\
\hline
\end{tabular}

Notes: -, low; +, high; CHRV, condemnation of human rights violations; GRI, Generalization of Risks Index; V, victimization; RMSEA, Root Mean Square Approximation; CFI, Confirmatory Fit Index; SRMR, Standardized Root Mean Square Residual.

All models were controlled for respondent's age, gender, level of education, experience of war victimization, and having been a combatant. The reference category for the ethno-national group regression coefficients is "other." Anomie in the context-level section refers to the between-contexts variance of anomie, which in Mplus is estimated as a latent construct.

${ }^{\dagger} p<.10 ; * p<.05 ; * * p<.01 ; * * * p<.001$.

we find that the communities that suffered the most from generalized violence also report higher levels of anomie. These findings suggest that living in a social environment where norms are challenged by forms of violence that problematize the distinction between ingroup and outgroup experience may, in turn, trigger a heightened sensitivity to restoring rights that transcends group boundaries and perhaps prevents future traumatic experiences.

This result has practical consequences. Vollhardt and Bilali (2015) argued that people who acknowledge that both opposing groups in a conflict were victimized are also more likely to support leaders who promote the interests of all ethnic groups rather than the exclusive rights of their own group. Such inclusive victim awareness may also be encouraged through intergroup contact. For instance, when victims share their stories regarding their experiences of victimization across group boundaries (Andrighetto, Mari, Volpato, \& Behluli, 2012), they generate mutual knowledge that plays an important role in the process of progressing toward a more just and inclusive conflict aftermath.

At the theoretical level, our research reaffirms the fruitfulness of a social representation approach to the attitudes toward human rights (Elcheroth, Doise, \& Reicher, 2011; Spini \& Doise, 2005), in which shared understandings of human rights are anchored in 
collective dynamics. We propose that the experience of generalized violence, with victims from all areas, is qualitatively different from the experience of particularized violence and that this difference triggers qualitatively different processes of social and political attitude formation. The correlational study presented here cannot causally describe such a model, but the replication of the empirical pattern that a higher generalization of risks of victimization across groups is related to higher levels of CHRV questions traditional models of cycles of violence during intractable conflicts, which are typically inferred from cases of highly asymmetric conflict (see Elcheroth \& Spini, 2015). Many features distinguish symmetric and asymmetric conflicts (Penic, 2014), notably the fact that in more symmetric conflicts, across different sides of the conflict, groups to which individuals belong or refer to (i.e., family, ethnic groups, state institutions, etc.) can no longer fulfill protective functions that legitimize their authority over individual conduct. By showing how the resulting climate of anomie can function as fertile ground for reinvigorating the human rights idea, the present findings shed new light on the paradox (Turner, 2006) that human rights are anchored in the most socially disruptive and most traumatic shared experiences.

\section{Acknowledgements}

This publication benefited from financial support of the Swiss National Science Foundation (SNSF grant number: 100012-109623) and was developed within the framework of the Swiss National Centre of Competence in Research LIVES-Overcoming vulnerability: Life course perspectives (NCCR LIVES, SNSF grant number: 51 NF40160590). The authors are grateful to the Swiss National Science Foundation for its financial assistance.

\section{References}

Ådnanes, M. (2007). Social transitions and anomie among post-communist Bulgarian youth. Young, 15, 49-69. https://doi.org/10.1177/1103308807072684

Andrighetto, L., Mari, S., Volpato, C., \& Behluli, B. (2012). Reducing competitive victimhood in Kosovo: The role of extended contact and common ingroup identity. Political Psychology, 33, 513-529. https://doi.org/10.1111/j.14679221.2012.00887.x

Archer, D., \& Gartner, R. (1984). Violence and crime in crossnational perspective. New Haven, CT: Yale University Press.

Arriaza, L., \& Roht-Arriaza, N. (2008). Social reconstruction as a local process. International Journal of Transitional Justice, 2, 52-172. https://doi.org/10.1093/ijtj/ijn010

Baumer, T. L. (2007). Reducing lockup crowding with expedited initial processing of minor offenders. Journal of Criminal Justice, 35, 273-281. https://doi.org/10.1016/j.jc rimjus.2007.03.004

Beck, U. (1992). Risk society: Towards a new modernity. London, UK: Sage.
Bernard, T. J. (1987). Testing structural strain theories. Journal of Research in Crime and Delinquency, 24, 262-280. https://doi.org/10.1177/0022427887024004002

Bjarnason, T., Thorlindsson, T., Sigfusdottir, I. D., \& Welch, M. R. (2005). Familial and religious influences on adolescent alcohol use: A multi-level study of students and school communities. Social Forces, 84, 375-390. https:// doi.org/10.1353/sof.2005.0088

Bollen, K. (1989). Structural equations with latent variables. New York, NY: Wiley.

Broz, S. (2005). Good people in an evil time: Portraits of complicity and resistance in the Bosnian War. New York, NY: Other Press.

Chwe, M. S. Y. (2013). Rational ritual: Culture, coordination, and common knowledge. Princeton, NJ: Princeton University Press.

Clark, L. A., \& Watson, D. (1995). Constructing validity: Basic issues in objective scale development. Psychological Assessment, 7, 309. https://doi.org/10.1037/1040-3590.7. 3.309

Crutchfield, R., \& Bates, K. A. (2000). Anomie. In E. F. Borgatta \& R. J. V. Montgomery (Eds.), Encyclopedia of sociology (Vol. 1, 2nd ed., pp. 164-168). New York, NY: Macmillan Reference USA.

Doise, W. (1988). Psychologie sociale et éthique des droits de l'homme [Social psychology and ethics of human rights]. In J. Iliopoulos-Strangas (Ed.), Annales 1986 de la Fondation Marangopoulos pour les droits de l'homme (pp. 108-124). Athens, Greece: Sakkoulas.

Doise, W., Dell'Ambrogio, P., \& Spini, D. (1991). Psychologie sociale et droits de l'homme [Social psychology and human rights]. Revue Internationale de Psychologie Sociale, 4, 257-277.

Doise, W., Spini, D., \& Clémence, A. (1999). Human rights studied as social representations in a crossnational context. European Journal of Social Psychology, 29, 1-30. https://doi.org/10.1002/(issn)1099-0992

Durkheim, E. (1951). Suicide: A study in sociology. Glencoe, IL: Free Press (Original work published 1897).

Elcheroth, G. (2006). Individual-level and community-level effects of war trauma on social representations related to humanitarian law. European Journal of Social Psychology, 36, 907-930. https://doi.org/10.1002/(issn) 1099-0992

Elcheroth, G., Doise, W., \& Reicher, S. (2011). On the knowledge of politics and the politics of knowledge: How a social representations approach helps us rethink the subject of political psychology. Political Psychology, 32, 729-758. https://doi.org/10.1111/j.1467-9221.2011. 00834.x

Elcheroth, G., Penic, S., Fasel, R., Giudici, F., Glaeser, S., Joye, D., Le Goff, J.-M., ... Spini, D. (2013). Spatially weighted context data and their application to collective war experiences. Sociological Methodology, 43, 364-411. https://doi.org/10.1177/0081175013486757

Elcheroth, G., \& Spini, D. (2007). Classes sociales et jugements normatifs de jeunes français: La justification du système par les défavorisés revisitée [Social classes and normative judgments of French youth: The disadvantageds' system justification revisited]. Les Cahiers Internationaux de Psychologie Sociale, 75, 117-131. https://doi.org/ 10.3917/cips.075.0117 
Elcheroth, G., \& Spini, D. (2009). Public support for the prosecution of human rights violations in the former Yugoslavia. Peace and Conflict: Journal of Peace Psychology, 15, 189214. https://doi.org/10.1080/10781910902837321

Elcheroth, G., \& Spini, D. (2015). Can there be a general theory of intractable conflicts? In E. Halperin \& K. Shervit (Eds.), The social psychology of intractable conflicts. Celebrating the legacy of Daniel Bar-Tal (Vol. 1, pp. 17-29). New York, NY: Springer. https://doi.org/10.1007/978-3319-17861-5

Enders, C. K., \& Tofighi, D. (2007). Centering predictor variables in cross-sectional multilevel models: A new look at an old issue. Psychological Methods, 12, 121. https://doi.org/10.1037/1082-989x.12.2.121

Fasel, R., \& Spini, D. (2016). Trajectoires d'exclusion et de bien-être d'une jeune cohorte qui a traversé les guerres en exYougoslavie [Trajectories of exclusion and well-being of a young cohort living the war in former Yugoslavia]. (LIVES Working Papers, 2016/47). https://doi.org/10. 12682/lives.2296-1658.2011.4

Hair, J. F., Tatham, R. L., Anderson, R. E., \& Black, W. (2006). Multivariate data analysis (Vol. 6). Upper Saddle River, NJ: Pearson Prentice Hall.

Honaker, J., Joseph, A., King, G., Scheve, K., \& Singh, N. (1999). Amelia: A program for missing data. Cambridge, MA: Harvard University.

Hwang, P., \& Burgers, W. P. (1999). Apprehension and temptation the forces against cooperation. Journal of Conflict Resolution, 43, 117-130. https://doi.org/10.1177/ 0022002799043001007

King, G., Honaker, J., Joseph, A., \& Scheve, K. (2001). Analyzing incomplete political science data: An alternative algorithm for multiple imputation. American Political Science Review, 95, 49-69.

Marsh, H. W., Ludtke, O., Robitzsch, A., Trautwein, U., Asparouhov, T., Muthen, B., \& Nagengast, B. (2009). Doubly-latent models of school contextual effects: Integrating multilevel and structural equation approaches to control measurement and sampling error. Multivariate Behavioral Research, 44, 764-802. https://doi.org/10.1080/ 00273170903333665

McClosky, H., \& Schaar, J. H. (1965). Psychological dimensions of anomy. American Sociological Review, 30, 14-40. https://doi.org/10.2307/2091771

Merton, R. K. (1957). Social theory and social structure. New York, NY: Free Press.

Morselli, D., Spini, D., \& Devos, T. (2012). Human values and trust in institutions across countries: A multilevel test of Schwartz's hypothesis of structural equivalence. Survey Research Methods, 6, 49-60. http://dx.doi.org/10. 18148/srm/2012.v6i1.5090

Muthén, L. K., \& Muthén, B. (1998-2013). Mplus user's guide. Los Angeles, CA: Author.

Penic, S. (2014). Collective victimisation and collective guilt in the former Yugoslavia: The interplay between individual, local and societal levels (Doctoral Dissertation). University of Lausanne, Lausanne, Switzerland.

Penic, S., Elcheroth, G., \& Morselli, D. (2017). Inter-group forgiveness in the aftermath of symmetric and asymmetric communal violence: Contact density and nationalistic climates as contextual mediators. European Journal of
Social Psychology, 47, 209-227. https://doi.org/10.1002/ ejsp. 2248

Penic, S., Elcheroth, G., \& Spini, D. (2018). When is collective exposure to war events related to more acceptance of collective guilt? Journal of Conflict Resolution, 62, 143173. https://doi.org/10.1177/0022002716645388

Perko, T., Turcanu, C., derSchrö, J., \& Carlé, B. (2010). Risk perception of the Belgian population. Results of the public opinion survey in 2009. Mol, Belgium: Belgian Nuclear Research Centre.

Preacher, K. J., Zyphur, M. J., \& Zhang, Z. (2010). A general multilevel SEM framework for assessing multilevel mediation. Psychological Methods, 15, 209-233 https://doi.org/10.1037/a0020141

Reicher, S. (2004). The context of social identity: Domination, resistance and change. Political Psychology, 25, 921946. https://doi.org/10.1111/j.1467-9221.2004.00403.x

Ringdal, K., \& Simkus, A. (2012). The aftermath of war: Experiences and social attitudes in the Western Balkans. Farnham, UK: Ashgate.

Rubin, D. B. (1987). Multiple imputation for nonresponse in surveys. New York, UK: Wiley \& Sons. https://doi.org/10. 1002/series 1345

Schafer, J. L. (1997). Analysis of incomplete multivariate data. London, UK: Chapman \& Hall. https://doi.org/10.1201/ chmonstaapp

Schafer, J. L., \& Olsen, M. K. (1998). Multiple imputation for multivariate missing-data problems: A data analyst's perspective. Multivariate Behavioral Research, 33, 545-571. https://doi.org/10.1207/s15327906mbr3304_5

Seeman, M. (1991). Alienation and anomie. In J. P. Robinson, P. R. Shaver \& L. S. Wrightsman (Eds.), Measures of personality and social psychological attitudes (Vol. 1, pp. 291371). San Diego, CA: Academic Press. https://doi.org/10. 1016/b978-0-12-590241-0.50011-3

Sekulic, D., Massey, G., \& Hodson, R. (2006). Ethnic intolerance and ethnic conflict in the dissolution of Yugoslavia. Ethnic and Racial Studies, 29, 797-827. https://doi. org/10.1080/01419870600814247

Silber, L., \& Little, A. (1997). Yugoslavia: Death of a nation (3rd ed.). New York, NY: Penguin Books.

Somasundaram, D. (2014). Addressing collective trauma: Conceptualisations and interventions. Intervention, 12, 43-60.

Spini, D., \& Doise, W. (2005). Universal human rights and duties as normative social representations. In N. J. Finkel \& F. Moghaddam (Eds.), The psychology of human rights and duties: Empirical contributions and normative commentaries (pp. 21-48). Washington, DC: American Psychological Association. https://doi.org/10.1037/10872000

Spini, D., Elcheroth, G., \& Corkalo Biruski, D. (2014). War, community, and social change. New York, NY: Springer. https://doi.org/10.1007/978-1-4614-7491-3

Spini, D., Elcheroth, G., \& Fasel, R. (2008). The impact of group norms and generalization of risks on judgments of war behavior. Political Psychology, 29, 919-941. https://d oi.org/10.1111/j.1467-9221.2008.00673.x

Spini, D., Elcheroth, G., \& Fasel, R. (2011). TRACES: Methodological and technical report (LIVES Working Papers, 2011/4). https://doi.org/10.12682/lives.2296-1658.2011.4 
Staerklé, C., \& Clémence, A. (2004). Why people are committed to human rights and still tolerate their violation: A contextual analysis of the principle-application gap. Social Justice Research, 17, 389-406. https://doi.org/10. 1007/s11211-004-2058-y

Staub, E. (2003). The psychology of good and evil: Why children, adults, and groups help and harm others. Cambridge, UK: Cambridge University Press. https://doi.org/10.1017/cb o9780511615795

Steenkamp, C. (2005). The legacy of war: Conceptualizing a "culture of violence" to explain violence after peace accords. The Round Table, 94, 253-267.

Thorlindsson, T., \& Bernburg, J. G. (2004). Durkheim's theory of social order and deviance: A multi-level test. European Sociological Review, 20, 271-285. https://doi.org/10. 1093/esr/jch025

Turner, B. (2006). Vulnerability and human rights. Philadelphia, PA: The Pennsylvania State University.

Tymms, P. (2004). Effect sizes in multilevel models. In I. Schagen \& K. Elliot (Eds.), But what does it mean? The use of effect sizes in educational research (pp. 55-66). London, UK: National Foundation for Educational Research.

Vollhardt, J. R., \& Bilali, R. (2015). The role of inclusive and exclusive victim consciousness in predicting intergroup attitudes: Findings from Rwanda, Burundi, and DRC. Political Psychology, 36, 489-506. https://doi.org/10. $1111 /$ pops. 12174

Whitt, S., \& Wilson, R. K. (2007). The dictator game, fairness and ethnicity in postwar Bosnia. American Journal of Political Science, 51, 655-668. https://doi.org/10.1111/j. 1540-5907.2007.00273.x

Wilmer, F. (2002). The social construction of man, the state, and war: Identity, conflict, and violence in former Yugoslavia. New York, NY: Routledge.

Zhao, R., \& Cao, L. (2010). Social change and anomie: A cross-national study. Social Forces, 88, 1209-1230. https://doi.org/10.1353/sof.0.0312

\section{Appendix}

\section{Violation of Judicial Rights}

In the context of a large-scale criminal affair, which causes serious problems for the national economy and the ruin of many people, an individual is charged with illegal activities. After two years of investigations and hearings, judges from a first court withdraw, invoking political and public pressures. One year later, hearings are resumed in a second court whose chairperson publicly expresses that he does not believe the accused to be innocent. When the work of the trial finally comes to an end, more than six years have passed, and the accused has spent most of this period in prison, granted the opportunity neither to meet with his family nor to correspond confidentially with his lawyers. However, according to the government of this country, the treatment of the accused was fully justified, given the outstanding severity and complexity of the accusation, the obvious plausibility that the accused is guilty, and the risk that he could flee.

\section{Violation of Social Rights}

If employees are required to work too many hours a week, they are at risk of not having enough time to rest and of experiencing problems reconciling their professional lives with their family lives. However, in one European country, no law forbids employees with certain responsibilities from working up to 78 hours a week. This implies that many of them have working weeks that go far beyond those of other types of employees. However, according to the government of this country, the fact that the national law requires each employee to stop working for at least 11 hours a day and at least once a week during 35 consecutive hours should be enough to assure convenient times for rest.

\section{Violation of Humanitarian Rights}

During the war, while attacking some towns and villages in areas where people of different national origins live, one army uses artillery and infantry against civilian targets, resulting in the deaths of numerous inhabitants, including women and children, and in the destruction of entire villages. A large number of civilians are rounded up and detained in makeshift camps where conditions are extremely harsh. Soldiers destroy and plunder, specifically targeting religious and educational buildings.

According to some people, these acts followed a common design to ethnically cleanse the area under attack. However, according to the responsible military leaders, the purpose of the action was to protect their own population from being subject to persecution. 